\title{
A ECOCRÍTICA FEMINISTA EM PURPLE HIBISCUS DE CHIMAMANDA NGOZI ADICHIE
}

\author{
FEMINIST ECOCRITICISM IN PURPLEHIBISCUS BY CHIMAMANDA NGOZI ADICHIE
}

\section{RESUMO}

Este artigo tem por objetivo analisar Purple Hibiscus, de Chimamanda Ngozi Adichie (2012), a partir da perspectiva da ecocrítica feminista, com embasamentos em Alaimo (2010), Brandão (1997, 2003, 2017, 2019), Gaard (2017) e Walker (1997), com referências também a outras/os autoras/es. A análise literária aborda a integração entre os seres - humanos e mais-que-humanos -, considerando que a natureza não é um cenário, mas parte integrante dos eventos e sentimentos relacionados às personagens. $\mathrm{O}$ romance trata da trajetória da protagonista em meio a um contexto conservador e patriarcal de opressão, violência, discriminação e embates culturais.

Palavras-chave: Literatura. Ecocrítica feminista. Violência.

\section{ABSTRACT}

The purpose of this paper is to analyze Purple Hibiscus, by Chimamanda Ngozi Adichie (2012), from the perspective of feminist ecocriticism, with theoretical foundations on Alaimo (2010), Brandão (1997, 2003, 2017, 2019), Gaard (2017), and Walker (1997), including references to other authors as well. The literary analysis addresses the interaction among beings - humans and more-than-humans-, considering that nature is not a landscape, but a part of events and feelings related to the characters. The novel shows the protagonist's trajectory amidst a conservative patriarchal context of oppression, violence, discrimination and cultural conflicts.

Keywords: Literature. Feminist ecocriticism. Violence.

Everything is a human being. Alice Walker

Este artigo analisa aspectos do romance Purple Hibiscus, ${ }^{1}$ de Chimamanda Ngozi Adichie (2012), traçando considerações a partir da perspectiva da ecocrítica feminista. Segundo Brandão (2003), o termo "ecocrítica", cunhado em 1978, referese a conceitos vinculados à ecologia e ao estudo da literatura. A autora faz uma explanação sobre a ecocrítica e suas abordagens desde a década de 7o. Ruekert (apud

1 Referência em português: ADICHIE, Chimamanda Ngozi. (2011). Hibisco roxo. Tradução Julia Romeu. São Paulo: Companhia das Letras, Edição Kindle. Todas as citações literárias do romance são extraídas do original em inglês, com as traduções correspondentes em rodapé, retiradas do texto publicado em português.

Raquel D'Elboux Nunes

Universidade Federal de Alagoas. Email: rdelbouxnunes@gmail.com 
Brandão, 2003: 462) define a ecocrítica como "a aplicação da ecologia e de conceitos ecológicos ao estudo da literatura”. O ecofeminismo - também "ecocrítica feminista" (Brandão, 2019) - surgiu nos anos 1990 em várias vertentes, sendo ainda um campo pouco estudado no Brasil.

A ecocrítica feminista, portanto, é uma vertente da ecocrítica. Greta Gaard, Simon Stock e Serpill Opperman (2013) esclarecem que a ecocrítica feminista aborda múltiplas vozes que chamam atenção para questões como justiça sexual e justiça ambiental, questões pós-coloniais e pós-humanas em relação a discussões sobre poder, gênero, ecologia e teoria queer, além de tratar dos papéis que mulheres exercem nas esferas sociais, ambientais e interespécies. ${ }^{2}$ Em razão disso, abre-se à interdisciplinaridade. Brandão (2017), em estudo do trabalho de Gaard e de outras/ os teóricas/os, aponta que o termo não deve ser entendido com bases essencialistas, ${ }^{3}$ mas com base em seu caráter interseccional.

Brandão \& Lourenço (2019) apontam a relevância do diálogo da perspectiva da ecocrítica feminista com vários campos de estudo, não se limitando à análise literária vinculada a conceitos ecológicos:

No contexto da literatura, pode-se afirmar que a ecocrítica feminista não se restringe a lidar com o texto literário de autoria feminina, ou com textos compreendidos como "ecofeministas" ou "feministas". A proposta dessa crítica traz um contexto mais democrático e aberto, pois aponta para a redefinição de determinados conceitos, a exemplo de "natureza", em suas várias acepções e diálogos. Dada a abertura da área à perspectiva interdisciplinar, muitas outras correntes teóricas servem também de suporte aos estudos ecocríticos feministas e feministas de modo mais geral. (Brandão \& Lourenço, 2019: 14).

Assim, a interdisciplinaridade é um eixo fundamental para a perspectiva da ecocrítica feminista, que traz discussões nos âmbitos da sociologia, da filosofia e de outras áreas, com impactos para o ativismo político, uma vez que "o contexto da ecologia faz parte das lutas democráticas e nem mesmo a crítica literária escapa às renovações" (Brandão, 2019: 14).

Neste trabalho, apresento reflexões a respeito da natureza, que não figura como cenário em Purple Hibiscus, mas que tem importância significativa no desenrolar dos acontecimentos, por integrar-se aos sentimentos e às ações das personagens. A

2 Segundo Gaard (2017), o ecofeminismo é um movimento amplamente articulado por ativistas, muitas das quais são pesquisadoras e escritoras, com uma combinação de identidades como "de primeiro mundo, branca, classe média, vegana/o ou vegetariana/o, lésbica ou bissexual”, ao passo que "porta-vozes de mulheres ativistas da justiça ambiental tendem a ser mulheres de cor, heterossexuais e onívoras/os" (Gaard, 2017: 792). Devido a essas múltiplas identidades e tensões multidirecionais a respeito de homofobia, especismo, classismo e racismo, é difícil formar alianças, segundo a teórica. A autora (Gaard, 2017) aponta que essas diferenças podem ser favoráveis, por terem em comum o combate à discriminação, e por terem compromisso com a práxis.

3 Ver nota 30. 
autora da obra, Chimamanda Ngozi Adichie, de origem nigeriana e residente nos Estados Unidos, é hoje referência midiática do feminismo negro, tendo publicado contos, romances e escritos de cunho teórico-feminista. We Should All Be Feminists ${ }^{4}$ é um ensaio adaptado de um discurso feito pela autora no TEDx Euston, ${ }^{5}$ que conta com milhões de visualizações e foi musicado por Beyoncé. ${ }^{6}$

Purple Hibiscus, publicado em 2003, tem feição autobiográfica e traz questões como opressão, violência, diferenças culturais, discriminação de gênero, classe social e etnia. $\mathrm{O}$ romance trata da conquista da mulher negra pela própria voz no contexto patriarcal, conservador e opressor. A protagonista Kambili mostra como seu pai, colonizado católico e membro respeitado da comunidade religiosa, rejeita as tradições nigerianas e agride a família. A obra apresenta o cenário da colonização invasora na Nigéria, com embates culturais, além de níveis de violência diversos, muitas vezes velada.

Nesse cenário, é recorrente e evidenciada a presença da natureza, não como pano de fundo, mas como parte integrante dos eventos e sentimentos relacionados às personagens. A análise literária, assim, considera a natureza também como personagem, também como "ser".

Na esteira dos estudos ecocríticos feministas, para a análise literária proposta neste trabalho, a natureza está constantemente atrelada aos movimentos e sensações das personagens e, também, à opressão. Na passagem citada a seguir, os hibiscos do jardim da família eram arrancados às vezes por visitantes e, muitas vezes, pela própria mãe da protagonista negra, Kambili:

They seemed to bloom so fast, those red hibiscuses, considering how often Mama cut them to decorate the church altar and how often visitors plucked them as they walked past to their parked cars. It was mostly Mama's prayer group members who plucked flowers; a woman tucked one behind her ear once [...]. But even the government agents, two men in black jackets who came some time ago, yanked at the hibiscus as they left (Adichie, 2012: 9). ${ }^{7}$

As flores são arrancadas por pedestres, por membros da igreja, e até por funcionários do governo. Segundo Walker (1997), a opressão de um ser não acontece isoladamente, uma vez que há interligação entre eles. Considero que o ato de arrancar ${ }_{4}$ Referência em português: ADICHIE, Chimamanda Ngozi (2015). Sejamos todos feministas. São Paulo: Companhia das Letras.

5 TedxEuston talk (2012), conforme registro em www.medium.com/@TEDxEuston. Acesso em: 20 de maio de 2020.

6 Música de 2013, conforme www.theguardian.com/books/2013/dec/13/beyoncee. Acesso em: 20 de maio de 2020.

7 "Eles surgiam tão rápido, aqueles hibiscos vermelhos, apesar de Mama cortá-los com frequência para decorar o altar da igreja e de as visitas sempre pegarem alguns a caminho de seus carros. Os membros do grupo de oração de Mama eram os que mais pegavam as flores; certa vez uma mulher colocara uma delas atrás da orelha [...]. Mas até os agentes do governo, dois homens de jaqueta preta que haviam aparecido lá, arrancavam hibiscos quando estavam indo embora" (Adichie, 2011: 97). 
as flores pode ser considerado um ato violento, sob essa perspectiva. Em contraponto, as flores resistem, ao florescerem novamente. Essa resistência pode ser associada ao pensamento de Alaimo (2010), de que existe agência por parte da natureza. A autora defende que os corpos humanos e mais-que-humanos ${ }^{8}$ interagem com as forças materiais, sociais, ecológicas, políticas e culturais, e que o meio ambiente não está simplesmente situado lá fora, mas faz parte de nossa própria substância. Analisando textos de Val Plumwood e Karen Barad, entre outras teorias, Alaimo (2010) aponta que não existe um sujeito, dotado de agência, que seja separado do meio ambiente. A natureza faz parte de nós, assim como nossa própria pele. Segundo a autora, a transcorporalidade refere-se à integração e ao intercâmbio entre corpos - entre várias naturezas corpóreas. ${ }^{9}$ A matéria por si é viva, não passiva, e denota um mundo material agente.

$\mathrm{Na}$ passagem do romance apresentada, as flores, como material agente, resistem e florescem novamente. A família também resiste a um patriarca repressor. A esposa agredida é aparentemente resignada e submissa, o que pode ser notado no trecho a seguir, quando ela se ocupa normalmente dos serviços domésticos e da família, pouco tempo após sofrer uma violência do esposo: "There were never tears on her face. The last time, only two weeks ago, when her swollen eye was still the blackpurple color of an overripe avocado [...]”"10 (Adichie, 2012: 10). Nessa passagem, a cor roxa remete à violência. ${ }^{11}$ No entanto, o texto parece desconstruir essa referência, pois os hibiscos roxos criados por Ifeoma referem-se à uma nova configuração das coisas, por meio da ciência e do conhecimento, relacionados à liberdade, conforme trato adiante. Pode-se entender a violência contra a esposa como produto da sociedade patriarcal (Humm, 1989), que no romance reverbera também na violência contra a natureza: ${ }^{12}$

A feminist theory proves that violence against women is pervasive and that it is the product of a patriarchal culture in which men control both social institutions and women's bodies ...Violence

80 termo "mais-que-humano" é utilizado no entendimento de que "não humano" implicaria numa dualidade entre seres humanos propriamente ditos e outras formas de vida (Gaard: 2017). A perspectiva da análise supera essa dualidade. O humano e o mais-que-humano coexistem, interagem e provocam impactos mútuos. Alaimo (2017: 910) aponta que o “ambiente', quase sempre imaginado como um espaço inerte e vazio ou como um 'recurso' para uso humano, é, de fato, um mundo de seres carnais, com suas próprias necessidades, exigências e ações". Para definir o "mais-que-humano", a autora propõe a transcorporalidade, que "abre um 'espaço' epistemológico que reconhece as muitas vezes imprevisíveis e indesejáveis ações dos corpos humanos, das criaturas não humanas, dos sistemas ecológicos, dos agentes químicos e de outros atores" (Alaimo, 2017: 910). Para aprofundamentos e indicações de leituras, ver Gaard (2017) e Alaimo (2017). Referências completas ao final.

9 Em inglês: bodily natures, termo que dá nome ao livro citado.

10 "Nunca havia lágrimas em seu rosto. Da última vez, há apenas duas semanas, quando seu olho inchado ainda estava da cor preto-arrouxeada de um abacate maduro demais [...]" (Adichie, 2011: 118).

11 A cor roxa como símbolo da violência está presente no romance $A$ cor púrpura, de Alice Walker (1982). Referência completa: WALKER, Alice. (2016). A cor púrpura. Tradução de Betúlia Machado et. al. Rio de Janeiro: Jose Olímpio.

12 Ver nota 3o, sobre o possível caráter essencialista da associação e sua refutação. 
against women is both a means of women's subordination and part of institutional and ideological domination (Humm, 1989:230-231). ${ }^{3}$

Apesar da aparente passividade e submissão da mãe de Kambili, ela, de certa forma, também compactua com a violência, ao arrancar as flores e ao ser conivente com as agressões do esposo contra os filhos. Ao final da narrativa, a esposa agredida mata o esposo. $\mathrm{O}$ arrancar das flores anteriormente pode ser lido com um prenúncio desse assassinato, como uma metáfora do ato de arrancar as raízes do patriarcado e da opressão.

Essa opressão é exercida pelo patriarca contra a mulher e contra as crianças, reverberando na natureza. Por sua vez, a mulher pratica a violência contra a natureza, e também se omite quando testemunha a agressão do esposo contra os filhos. Segundo o pensamento de hooks (2015), numa estrutura de poder, os grupos, em relação a outros grupos, exercem papéis de opressor e de oprimido. A autora analisa a posição particular das mulheres negras, que parecem não ter um grupo contra o qual se tornariam opressoras:

Nós, mulheres negras sem qualquer "outro" institucionalizado que possamos discriminar, explorar ou oprimir, muitas vezes temos uma experiência de vida que desafia diretamente a estrutura social sexista, classista e racista vigente, e a ideologia concomitante a ela. Essa experiência pode moldar nossa consciência de tal maneira que nossa visão de mundo seja diferente da de quem tem um grau de privilégio (mesmo que relativo, dentro do sistema existente) [...] (hooks, 2015: 208).

Por analogia, pode-se entender que a mãe de Kambili não tem poder sobre outros grupos, por estar situada num ambiente sexista e patriarcal, sob a dominação violenta do esposo. O outro oprimido para ela é a natureza, em atos violentos que prenunciam o assassinato do marido.

Segundo aponta o estudo de Greta Gaard (2017), alguns estudos, como os de Simon Estok e Timothy Morton, abordam interseccionalmente a relação de opressão entre natureza, sexualidade e gêneros. A autora menciona, inclusive, bell hooks, que constrói uma teoria inclusiva a partir de uma perspectiva marginalizada. ${ }^{14}$ Assim, a abordagem ecológica também teria que partir de uma identificação com "perdedores, com o 'sub-humano', ao invés do super-homem” (Gaard, 2017: 797).

13 "A teoria feminista prova que a violência contra as mulheres é difundida por ser produto da cultura patriarcal na qual os homens controlam as instituições sociais e os corpos das mulheres. A violência contra as mulheres é tanto um meio de subordinação das mulheres, quanto parte da dominação institucional e ideológica" (Tradução nossa).

14 hooks (2000) assinala a importância de diferentes eixos identitários, como classe, etnia, religião, preferência sexual etc., fazendo-se necessária uma visão que explore novas possibilidades, o que é compatível com a feição interseccional. Referência completa: HOOKS, bell. (2000). Feminist theory: 
Porém, se considerarmos que todos os seres estão holisticamente integrados, como ressalta Walker (1997), entendemos que deve haver igualdade na vida e nos direitos, uma vez que existem também árvores, pessoas e animais. $\mathrm{O}$ trabalho de Morton (2007) também está em conformidade com esse pensamento, considerando que a ideia de "pessoas" não é restrita aos seres humanos. O autor assinala que "putting something called nature on a pedestal and admiring it from afar does for the environment what patriarchy does for the figure of woman. It is a paradoxical act of sadistic admiration" (Morton, 2007: 15). ${ }^{15}$ Essa perspectiva pós-humana contraria a visão de que os seres humanos, na qualidade de superiores, devem dominar as outras espécies.

Segundo Simcikova (2007), antes da revolução cartesiana, as religiões pagãs pregavam que o princípio animado (a alma) permeava todo o cosmos. Portanto, as plantas, os animais e os astros eram considerados seres vivos. No entanto, com o conceito dualista de matéria/espírito no pensamento ocidental, a alma foi retirada da natureza, e os seres humanos - dotados da racionalidade - tomavam os outros seres como objetos para exploração e dominação.

Podemos considerar, portanto, que a visão pós-humana refuta a construção cultural milenar da superioridade dos seres humanos em relação aos seres maisque-humanos, e também reforça o questionamento da superioridade dos homens em relação às mulheres, debatido nas teorias feministas.

No romance de Adichie, o patriarca insiste na dominação da família, tendo muitas vezes atitudes ameaçadoras. Quando contestado, reage com violência. É significativa a passagem mencionada a seguir referente à celebração religiosa do domingo de Ramos, pois é o dia em que o pai, zangado com Jaja por não ter participado da comunhão católica, quebra as estatuetas de que a esposa tanto gostava: "She spent at least a quarter of an hour on each ballet-dancing figurine"16 (Adichie, 2012: 10). No dia da quebra das estatuetas, o clima começa a ficar mais tenso:

Things started to fall apart at home when my brother, Jaja, did not go to communion and Papa flung his heavy missal across the room and broke the figurines on the étagère. We had just returned from church. Mama placed the fresh palm fronds, which where wet with holy water, on the dining table and then went upstairs to change. Later, she would knot the palm fronds into sagging cross shapes and hang them on the wall beside our gold-framed family photo. They would stay there until next Ash Wednesday, when we

from margin to center. Cambridge: South End Press.

15 " [C]olocar algo chamado de natureza num pedestal e admirá-la à distância faz para o meio ambiente o que o patriarcado faz com as mulheres. É um ato paradoxal de admiração sádica" (Tradução nossa).

16 "Ela dedicava pelo menos quinze minutos a cada estatueta de bailarina" (Adichie, 2011: 117). 
would take the fronds to church, to have them burned for Ash. [...] Papa [...] helped distribute ash every year (Adichie, 2012:3). ${ }^{17}$

Nesse trecho, aparecem as folhas de ramos, antes da Páscoa, conforme a tradição. Segundo a crença católica, o povo teria se utilizado de ramos para cobrir a passagem por onde passaria o líder - Jesus Cristo. Assim, os ramos simbolizariam sua entrada, pouco antes de ser morto na cruz. A família, no romance, também tem certa "entrada triunfal" ao voltar da igreja - com os ramos frescos, banhados à água benta, dispostos na mesa para o jantar. Porém, há também uma "morte" na família após o triunfo - as coisas começam a se degringolar nesse dia, quando o pai de Kambili quebra as estatuetas da mãe.

Essa violência reverbera na natureza. Considero que, do ponto de vista da ecologia, pode-se dizer que, de certa forma, há mutilação dos ramos, arrancados para um ritual religioso, assim como a família, que é mutilada pelo pai violento. Os ramos estão dispostos na mesa, para depois serem pendurados na parede, ao lado da foto da família. Posteriormente, seriam transformados em cinzas. Assim, passariam por uma metamorfose, questão que trato mais adiante. A família, aparentemente em paz, vai à igreja, tem a foto disposta na parede, mas no cerne do lar a violência impera. Esse degringolar familiar - quando a narradora diz que "things started to fall apart"18 também pode ser lido como uma metamorfose. Como as folhas de ramos, a estrutura familiar se desfaz. Assim, a natureza integra-se com os sentimentos e movimentos humanos.

A atmosfera que se sucede à quebra das estatuetas é tensa: "Everything came tumbling down after Palm Sunday. Howling winds came with the angry rain, uprooting frangipani trees in the front yard. They lay on the lawn, their pink and white flowers grazing the grass, their roots waving lumpy soil in the air"19 (Adichie, 2012: 257). Percebemos a associação da natureza nesse trecho - a árvore é agredida pelos ventos ferozes, assim como a esposa fora agredida pelo marido. Conjuga-se à essa análise a agência da natureza. Alaimo (2010: 144) estuda vários autores e várias autoras, em relação à agência de várias formas de vida, afirmando que a vida silvestre "can be considered a form of material agency, an agency without a (human) subject". ${ }^{20}$

17 "As coisas começaram a se deteriorar lá em casa quando meu irmão, Jaja, não recebeu a comunhão, e Papa atirou seu pesado missal em cima dele e quebrou as estatuetas da estante. Havíamos acabado de voltar da igreja. Mama colocou as palmas molhadas de água benta sobre a mesa de jantar e foi para o segundo andar da casa trocar de roupa. Mais tarde ela arrumaria as palmas na forma de cruzes e penduraria na parede ao lado da foto com moldura dourada de nossa família. As cruzes ficariam ali até a Quarta-Feira de Cinzas, quando levaríamos as palmas à igreja, para que elas fossem queimadas e transformadas em cinzas. [...] Papa [...] ajudava a distribuir cinzas todos os anos" (Adichie, 2011: 10).

18 "As coisas começaram a se deteriorar" (Adichie, 2011: 8).

19 "Tudo desmoronou após o Domingo de Ramos. Ventos uivantes vieram com uma chuva furiosa, arrancando algumas plumérias do jardim. Elas ficaram caídas sobre a grama, suas flores brancas e cor-de-rosa tocando o chão e as raízes à mostra com pedaços de terra oscilando no vento" (Adichie, 2011:3423).

20 "[P]ode ser considerada uma forma de agência material, uma agência sem um sujeito (humano)" (Tradução nossa). 
A agência e a significância de forças materiais no planeta e sua interface com as agências humanas e não-humanas, na era pós-humana, cada vez mais contestam a distinção entre os mundos humano e mais-que-humano e chamam a atenção para os intercâmbios entre corpos e a natureza (Opperman, 2012). A ética ambiental no pós-humanismo, segundo Alaimo (2010: 142), "refuses to see the delineated shape of the human as distinct from the background of nature, and instead focuses on interfaces, interchanges, and transformative material/discursive practices". ${ }^{21}$

Corpos humanos e mais-que-humanos têm uma abertura mútua - a transcorporalidade. Segundo Alaimo (2010: 2), “[...] the substance of the human is ultimately inseparable from the "environment" ${ }^{22} \mathrm{e}$ "the human is always intermeshed with the more-than-human world". ${ }^{23}$ A autora analisa um texto de Donna Haraway a respeito da teoria darwiniana sobre a semelhança entre seres humanos e outras criaturas, considerando que a "[...] physical relatedness [...] may provoke a rich ethical sense of kinship between the human and other animals [...]" (Alaimo, 2010: 151). ${ }^{24}$ Os corpos, portanto, são matéria ativa e não existem antes das relações materiais com seus ambientes, nem além dessas relações. Isso implica que o mundo material não é meramente um lugar externo. É a nossa própria substância.

Assim, é importante que se solidifique a nossa sintonia com o chamado "mundo exterior", uma vez que questões ecológicas preocupam o mundo todo (Brandão, 2003). A literatura é uma forma de se pensar essas questões. Em Adichie, após o Domingo de Ramos, passagem analisada acima, paira um clima de tensão na família: "There was something hanging over all of us. Sometimes I wanted it all to be a dream - the missal flung at the étagère, the shattered figurines, the brittle air" 25 (Adichie, 2012: 258). As coisas frágeis e quebradas se relacionam: os ramos, as estatuetas, a harmonia familiar. Até mesmo o ar aparentava fragilidade.

Pode-se notar, no texto, que o patriarca aprecia os feriados católicos, mas sua passividade e mansidão são aparentes, uma vez que suas atitudes são opressoras no âmbito familiar. O feriado do Natal era também valorizado por ele, que sempre levava a família nessa época para viajar. A esposa e os filhos se preparavam, seguindo suas ordens: "Papa stood by the hibiscus, giving directions, one hand sunk in the pocket of his white tunic while the other pointed from item to car"26 (Adichie, 2012: 53). O clima era tenso e as folhas da árvore eram arrancadas, assim como a família era arrancada de casa. O verbo "yank" no excerto seguinte significa "to pull (something)

21 "[R]ecusa-se a ver a forma delineada do humano distinta do histórico da natureza, focando-se nas interfaces, intercâmbios e práticas transformativas materiais/discursivas” (Tradução nossa).

22 “[...] a substância dos seres humanos é basicamente inseparável do "meio ambiente" (Tradução nossa).

23 “[...] o ser humano está sempre interligado com o mundo mais-que-humano [...]” (Tradução nossa). 24 “[...] semelhança física [...] pode provocar um sentido ético e fecundo de parentesco entre seres humanos e outros animais” (Tradução nossa).

25 "Algo pairava sobre todos nós. Às vezes eu queria que tudo fosse um sonho - o missal atirado na estante, as estatuetas despedaçadas, o ar quebradiço” (Adichie, 2011: 3432).

26 "Papa dava ordens ao lado dos arbustos de hibiscos, com uma das mãos enfiadas nos bolsos de sua túnica branca e outra apontando para os itens e para os carros” (Adichie, 2011: 648). 
forcefully with a quick movement”27 (Procter, 1995: 1695), i.e., houve força e violência, integralizadas às forças da natureza: "Dust-laden winds of harmattan came with December. They brought the scent of the Sahara and Christmas, and yanked the slender, ovate leaves from the frangipani the needlelike leaves from the whistling pines [...]" (Adichie, 2012: 52-53). ${ }^{28}$

A força exercida pelo vento faz dobrar as árvores: "The morning winds were swift on the day we left, pulling and pushing the whistling pine trees so that they bent and twisted, as if bowing to a dusty god [...]"29 (Adichie, 2012: 53). Aqui, é significativa a reverência a um deus (com letra minúscula) empoeirado. O deus já não serve; está empoeirado. A reverência forçada ao pai também já não pode servir, a partir de questionamentos e ressignificações. O pai, portanto, também seria um tipo de "deus empoeirado", a quem a subordinação passa a ser questionada.

Segundo Walker (1997), tudo no planeta faz parte de um todo, que ela chama de Deus, e todas as coisas vivas são o corpo e a alma desse Deus. Analisando o texto de Walker, Simcikova (2007) pondera que o capitalismo e o consumismo trazem destruição ao planeta, em nome do progresso, e a subordinação imposta à Terra estaria ligada à subordinação imposta às mulheres..$^{30} \mathrm{~A}$ autora pondera que "Walker's concept of holistic vision intertwined with that of equality in existence, in which humans animals, and plants, are all related as members of one Family", ${ }^{11}$ contesta a crença cristã de que seres humanos são superiores a outras espécies, que devem ser dominadas (Simcikova, 2007: 86). Todo tipo de subordinação, portanto, tem impactos no planeta.

Em Purple Hibiscus, a subordinação imposta pelo patriarca à família também tem impactos além do ambiente doméstico, reverberando na natureza, conforme já apontado. Parte dessa imposição é a rigidez do patriarca em relação à religião, fator de ameaça e medo. Quando Kambili está diante do padre para confessar seus pecados, a mando do pai, os olhos dele são comparados aos olhos de uma cobra: "I looked away from the wall to glance at him. His eyes were the same green shade of a snake I had

27 "[P]uxar (alguma coisa) com força, num movimento brusco" (Tradução nossa).

28 "Os ventos empoeirados do harmattan chegaram junto com o mês de dezembro. Eles trouxeram o cheiro do deserto do Saara e do Natal, e arrancaram as folhas finas e ovais das plumérias, e as folhas em forma de alfinete das casuarinas, cobrindo tudo de marrom" (Adichie, 2011: 641).

29 "Os ventos matinais estavam fortes no dia em que partimos, puxando e empurrando as casuarinas, deixando-as vergadas como quem faz reverência a um deus empoeirado [...]” (Adichie, 2011: 645).

30 A respeito da ligação entre a opressão da natureza e a exploração das mulheres, visão criticada por seu possível caráter essencialista, Brandão (2003 e 2019), em exposição teórica sobre a perspectiva teórica da ecocrítica feminista, esclarece a visão de várias autoras que refutam a feição essencialista dessa ligação. Susan Griffin e Ynestra King consideram que homens e mulheres estão sujeitos a forças culturais. Val Plumwood, Rose Braidotti e Donna Haraway defendem a necessidade de transformar "conceitos gendrados - natureza, cultura, corpo, mente, objeto, sujeito, fonte, agente, e outros - numa outra coisa, que não desautorize nem silencie certos grupos de humanos e também de vida não humana" (Brandão, 2019: 12-13).

31 "[O] conceito da visão holística de Walker, imbricado com o conceito de igualdade na existência, segundo o qual humanos, plantas e animais são considerados membros de uma família" (Tradução nossa). 
seen once, slithering across the yard near the hibiscus bushes"32 (Adichie, 2012: 105). Um dos "pecados" foi ter visitado o avô, que não era cristão, e ter gostado de observar rituais pagãos: "'You understand that it is wrong to take joy in pagan rituals, because it breaks the first commandment. Pagan rituals are misinformed superstition, and they are the gateway to Hell" (Adichie, 2012: 106).33

Os olhos do pai podem ser lidos como ameaçadores e também como traiçoeiros. Kambili fora forçada a confessar que traíra os ensinamentos cristãos do pai. Por outro lado, o pai também traíra sua herança cultural, ao abraçar o cristianismo, rejeitando suas origens e seu próprio pai. Há também uma traição aos próprios ensinamentos religiosos, pois ele pregava a paz na igreja, mas agia com violência no lar, contra seus filhos e sua esposa. Paradoxalmente, o próprio opressor fora colonizado, cabendo até mesmo a ponderação de que ele, de certa forma, também fora oprimido pelo processo de colonização e, com isso, tornou-se tão rigoroso a ponto de negar sua cultura nigeriana e seu próprio pai. O pai de Kambili tornou-se um rígido representante do colonizador. A mulher, os filhos e a natureza são para ele domináveis, com status de colonizado.

Em outra passagem do romance, a autoridade do patriarca se mostra nos preparativos de uma viagem, quando ele resolve mandar a filha e o filho para a casa de tia Ifeoma em Nsukka. As crianças, paradas ao lado dos hibiscos, observam o jardim e aguardam o pai terminar as preparações da viagem: "Jaja and I stood by the hibiscus bushes, waiting. [...] He [the gardener) had raked underneath the frangipani trees, and dead leaves and pink flowers lay in pleas, ready for the wheelbarrow" (Adichie, 2012: 108).34

Nessa passagem, as folhas mortas empilhadas, prestes a serem varridas, podem ser equiparadas às crianças que estavam ali, à mercê das ordens do pai, de certa forma também "varridas" para a casa da tia. Entretanto, nesse cenário, aparecem sinais de questionamento da autoridade do pai. Kambili olha as flores que desafiavam a árvore, por se projetarem acima da copa: "The gardener was clipping away at the bougainvillea, taming the flowers that defiantly stuck out of the leveled top" 35 (Adichie, 2012: 108). As flores desafiadoras lhe trazem a lembrança do dia em que Jaja desafiara o pai opressor, ao sair da mesa antes que terminassem as orações após a refeição:

32 "Desviei o olhar da parede e o encarei. Seus olhos tinham o mesmo tom de verde de uma cobra que eu vira certa vez deslizando pelo jardim perto dos hibiscos" (Adichie, 2011: 1381).

33 "Você precisa entender que é errado gostar de rituais pagãos, pois isso é desobedecer ao primeiro mandamento. Rituais pagãos são superstições falsas, e são a porta de entrada do inferno" (Adichie, 2011: 1390).

34 "Jaja e eu ficamos ao lado dos hibiscos, esperando. [...] Ele [o jardineiro] usara o ancinho para juntar as folhas mortas e as flores cor-de-rosa que haviam caído das plumérias, e as organizara em montes que estavam prontos" (Adichie, 2011: 1424).

35 "O jardineiro podava as buganvílias, domando as flores que despontavam desafiadoramente em seu topo nivelado" (Adichie, 2011: 1424). 
I reached for my glass and stared at the juice, watery yellow, like urine. I poured all of it down my throat, in one gulp. I didn't know what else to do. This had never happened before in my entire life, never. The compound walls would crumble, I was sure, and squash the frangipani trees. [...] My body shook from the coughing [...] (Adichie, 2012: 9)..$^{6}$

O medo que a garota sente é também transposto para as árvores, que seriam esmagadas pelas paredes, assim como ela se sentia esmagada. $\mathrm{O}$ enfrentamento ao pai pelo irmão pode ser relacionado às flores que desafiavam a árvore. A lembrança desse episódio com o irmão, ativada pelas flores, é relevante na viagem para a casa de Ifeoma, que tem papel significativo no questionamento da autoridade. A tia simboliza a irreverência e a contestação das normas impostas, relacionada à atitude de Jaja ao desafiar o pai. Por estar ligada à ciência, ${ }^{37}$ Ifeoma desenvolve experimentos com a cor dos hibiscos, que chamavam a atenção - os hibiscos roxos, que dão nome ao romance. Isso é bastante significativo porque a personagem de Ifeoma faz parte de uma categoria antes apenas permitida aos homens - a ciência. Percebe-se também uma crítica a essa prática cultural. A mudança nas cores dos hibiscos pela tia pode ser lida como uma metáfora para a mudança de paradigmas, para a necessidade de lançar novos olhares e ressignificar padrões impostos pela cultura patriarcal. Um desses padrões é a exclusão das mulheres do âmbito científico.

Jaja, ao ver esses hibiscos pela primeira vez, questiona a tia: "I didn't know there were purple hibiscus [...] o maka, so beautiful"38 (Adichie, 2012: 128). Ifeoma explica que realiza seus experimentos com uma amiga, que é professora de botânica. Dessa forma, associa-se à erudição, à liberdade e à capacidade de questionar autoridades que impõem padrões: "Jaja's defiance seemed to me now like Aunty Ifeoma's experimental purple hibiscus: rare, fragrant with the undertones of freedom, a different kind of freedom from the one the crowds waving green leaves chanted at Government Square after the coup. A freedom to be, to do".39 (Adichie, 2012: 15).

A "liberdade diferente" da tia e dos hibiscos experimentais simbolizam uma nova possibilidade de ver o mundo, uma esperança de libertação das amarras do patriarcado controlador, violento e opressor - uma metamorfose. Os hibiscos passam

36 "Peguei meu copo e olhei o suco, amarelo e aguado como urina. Bebi tudo de um só gole. Não sabia o que mais podia fazer. Em toda a minha vida aquilo jamais acontecera, nunca. Tive certeza que os muros da nossa casa iam desmoronar e esmagar as plumérias [...]. Meu corpo começou a sacudir por causa da tosse" (Adichie, 2011: 168).

37 Brandão usa uma cientista em condições diferentes, mas também conectadas com o contexto de violência, em análise de Pérolas absolutas, de Heloisa Seixas. Referência completa: BRANDÃO, Izabel. (2015). "Lugares heterotópicos e a constituição de corpos fronteiriços e identidades transitórias na narrativa de autoras contemporâneas". In: DALCASTAGNE, Regina; LEAL, Virginia (Orgs.). Espaço e gênero na literatura brasileira contemporânea. Porto Alegre: Editora Zouk.

38 "Não sabia que existiam hibiscos roxos [...]. Oh maka, tão lindos" (Adichie, 2011: 1695).

39 "A rebeldia de Jaja era como os hibiscos roxos experimentais da tia Ifeoma: rara, com o cheiro suave da liberdade, uma liberdade diferente daquela que a multidão, brandindo folhas verdes, pediu na Government Square após o golpe. Liberdade para ser, para fazer" (Adichie, 2011:192). 
por uma metamorfose, tanto explicitamente no experimento botânico, quanto no nível simbólico, ao representar essa possível liberdade e ressignificação de padrões.

A metamorfose é discutida por Brandão (1997), em análise do texto de Marjorie Perloff, que compara D. H. Lawrence, Sylvia Plath e Rimbaud. A autora trata a fenomenologia da metamorfose em Lawrence, analisando flores, animais, humanos e amantes, em dois poemas de Birds, Beasts and Flowers. Em Sicilian Cyclamens, os amantes vislumbram flores minúsculas, ao olharem para o solo. As flores não só simbolizam o mundo interior dos namorados, mas unem-se a esse mundo:

For the first time,

... tiny rose cyclamens between their toes...

A autora considera que as flores delicadas remetem à conexão dos amantes com um mundo definido pelo poeta como:

Dreamy, not yet present

Drawn out of earth

At his toes.

Nessa leitura, as flores sofrem uma metamorfose, por meio da imaginação do poeta, que as transforma quando confere a elas qualidades animadas, e também quando as aproxima das qualidades dos amantes que, como as flores, são inexperientes e aguardam a chegada de um novo dia. As flores, assim, ficam humanizadas (Brandão, 1997).

Nesse mesmo estudo, a autora aponta que Birds, Beasts and Flowers pode ser considerado um poema oracular, i.e., a voz do/a poeta é a voz do oráculo. Em contraponto à poesia inglesa desde Wordsworth, na poesia oracular a natureza não tem um caráter passivo. Em vez de a natureza figurar objetiva e esteticamente separada do sujeito, que tem atitude de contemplação, o/a poeta se identifica com tal objeto. Há um intercâmbio de lugares entre natureza e o/a autor/a - "Catharsis becomes ecstasis and the poet utters rather than addresses. Hence, the poet identifies him/herself with the object instead of seeing it out there"40 (Brandão, 1997: 32). Especificamente analisando alguns poemas de Lawrence, a autora considera que o poeta se integra com o mais-que-humanos e sua alma sofre uma metamorfose, não kafkiana, mas baseada na fenomenologia da imaginação, de Bachelard. ${ }^{41}$

Nesse mesmo sentido, no romance de Adichie, os objetos não estão "do lado de fora”. São integrados e identificados com os sentimentos e movimentos dos personagens, conforme apontei em alguns excertos da obra, havendo intercâmbio entre os seres.

A metáfora extremada da metamorfose e do intercâmbio entre os seres é a morte do patriarca. As frutas caem para apodrecer no chão, exalando um cheiro agridoce. O corpo de Papa também apodreceria na terra. As vidas humanas e as mais-que-humanas passam, assim, por uma metamorfose:

40 "A catarse torna-se êxtase e o poeta pronuncia algo, mais do que se dirige a alguém. Assim, o poeta se identifica com o objeto, em vez de vê-lo lá fora" (Tradução nossa).

41 Referências completas e embasamento teórico no artigo citado. 
Outside, the rain came down in slants, hitting the closed windows with a furious rhythm. It would hurl down cashews and mangoes from the trees and they would start to rot in the humid earth, giving us that sweet-and-sour scent. The compound gates were locked. Mama had told Adamu not to open the gates to all the people who wanted to throng in for mgbalu, to commiserate with us. Even members of our umunna who had come from Abba were turned away. Adamu said it was unheard off, to turn sympathizers away. But Mama told him we wished to mourn privately, that they could go to offer Masses for the repose of Papa's soul. I had never heard Mama talk to Adamu that way; I had never even heard Mama talk to Adamu at all (Adichie, 2012: 288)..$^{42}$

A natureza parece bater violentamente na janela, fazendo cair as frutas, que voltarão à terra, passando por uma metamorfose. Estão assim integradas às vidas humanas e mais-que-humanas. Essa integração está relacionada ao apagamento da barreira animal humano/mais-que-humano, defendida por Morton (apud Gaard, 2017: 797-798): "a ecologia sem a Natureza considera todos os seres como pessoas, ao mesmo tempo em que não restringe a ideia de 'pessoas' a seres humanos propriamente ditos".

Com a morte do marido, a esposa já começa a romper tradições, ao dar ordens que contradizem os costumes. Sem a presença opressora do esposo, aparece sua volição, o que causa estranhamento em Kambili, conforme passagem citada acima. A feição agridoce pode ser interpretada como a ambivalência da morte do patriarca a perda do pai admirado e temido em contraponto ao ganho da liberdade da esposa e dos filhos. Essa liberdade é relativa, pois, para proteger a mãe, Jaja assume o crime e cumpre pena durante três anos, o que causa sofrimento para a mãe e para a irmã. A mãe confessa o crime, mas não lhe é dada credibilidade. Sua liberdade e volição são limitadas - não consegue salvar totalmente os filhos, como era de seu desejo, e retraise. Kambili aos poucos se desfaz das amarras da opressão. A mãe torna-se retraída e quase não fala, mas tem importância significativa na liberdade conquistada pela filha. Ao final da narrativa, Kambili quer levar sua genitora e seu irmão para visitar Ifeoma, e depois cultivar laranjas e hibiscos roxos:

We'll plant new orange trees in Abba when we come back, and Jaja will plant purple hibiscus too, and I'll plant ixora so we can suck the juices of the flowers. I am laughing. I reach out and place

42 "Lá fora, a chuva caía em diagonais, batendo nas janelas fechadas num ritmo furioso. Ela arrancaria cajus e mangas das árvores, e eles começariam a apodrecer na terra úmida, exalando aquele odor agridoce. Os portões de nossa propriedade estavam trancados. Mama mandara Adamu não abri-los para as pessoas que vinham para o mgbalu, para lamentar conosco. Até membros da nossa umunna que tinham vindo de Abba foram barrados. Adamu disse que ninguém jamais tinha visto uma pessoa recusando entrada àqueles que vinham se solidarizar com ela. Mas Mama disse a ele que queríamos chorar sozinhos e que os outros podiam mandar rezar missas para que a alma de Papa descansasse em paz. Eu jamais tinha ouvido Mama falar com Adamu daquele jeito; jamais tinha ouvido Mama dirigir a palavra a Adamu" (Adichie, 2011: 3835). 
my arm around Mama's shoulder and she leans toward me and smiles. Above, clouds like dyed cotton wool hang low, so low I can feel I can reach out and squeeze the moisture from them. The new rains will come down soon (Adichie, 2012: 306-307).43

A menção ao plantio dos hibiscos roxos, inspirados nos experimentos de Ifeoma, simbolizam a conquista da liberdade, atrelada ao conhecimento científico. Pode-se notar a valorização da educação para o exercício da liberdade. Evidencia-se uma protagonista mais leve, que ri, por estar a caminho de uma vida mais autônoma e livre. As nuves de algodão trazem essa leveza. Até a mãe sorri, um indício de uma visão otimista para o futuro que se abria.

Neste breve estudo, analisei trechos da obra sob a perspectiva da ecocrítica feminista, segundo a qual os seres se interligam e interagem. Devemos pensar no planeta como parte de nós, e devemos pensar em nós mesmos/as como parte de outras formas de vida. Devemos refletir e estudar sobre o que tem causado tantos desastres ecológicos. Pensemos na agência da natureza, conforme colocações de Alaimo (2010), discutidas neste artigo. $\mathrm{O}$ que será do planeta que habitamos se comportamentos humanos continuarem sendo tomados como parâmetros para todos os tipos de vida e continuarmos insistindo na superioridade dos seres humanos?

Embora pouco estudada no Brasil, a abordagem ecocrítica não é recente. Gaard (2017) pondera que o feminismo ecológico não pertence a nenhuma "onda", como se dividem os feminismos, uma vez que o posicionamento que integra a ecologia aparece de várias formas desde o século XIX. A metáfora para estudos ecocríticos, em vez de "onda", poderia ser "palimpsesto", conforme nota de Gaard (2017: 784).

Segundo Brandão \& Lourenço (2019), a ecologia no palco permite a renovação dos olhares críticos, muito pertinente no cenário da atualidade, com questões ambientais na ordem do dia. Há muito a ser explorado para trilhar o caminho da ecocrítica feminista. É necessário promover discussões pertinentes em várias áreas de estudo, por seus impactos para o futuro do nosso planeta.

\section{Referências}

ADICHIE, Chimamanda Ngozi. (2011). Hibisco roxo. Tradução Júlia Romeu. São Paulo: Companhia das Letras, Edição Kindle. . (2012). Purple hibiscus. Chapel Hill: Algonquin Books.

43 "Vamos plantar laranjeiras novas em Abba quando voltarmos, e Jaja vai plantar hibiscos roxos também, e eu vou plantar ixoras para podermos sugar o suco das flores. Estou rindo. Coloco o braço em volta do ombro de Mama e ela se recosta em mim e sorri. Lá em cima nuvens que parecem algodão tingido pairam bem baixas, tão baixas que sinto que posso esticar o braço e espremer a água delas. As novas chuvas vão cair em breve" (Adichie, 2011: 4038). 
ALAIMO, Stacy. (2010). Bodily natures: science, environment, and the material self. Bloomington: Indiana University Press.

. (2017). "Feminismos transcorpóreos e o espaço ético da natureza". Estudos Feministas, n. 25, v. 2, p. 909-934. Florianópolis, maio-agosto.

BRANDÃO, Izabel. (1997). "Birds, beasts and flowers: towards a dialectics of metamorphosis”. Fragmentos, n. 7, v. 1, p. 32-54. Florianópolis, jul/dez.

. (2003). "Ecofeminismo e literatura: novas fronteiras críticas". In: BRANDÃO, Izabel.; MUZART, Zahidé (Orgs.). Refazendo nós: ensaios sobre mulher e literatura. Forianópolis e Santa Cruz do Sul: Mulheres e Editora da UFSC, p. 461-474.

(2017). "Greta Gaard e a busca de rumos mais feministas para os estudos ecocríticos”. In: BRANDÃO, Izabel et. al. (Orgs.) Traduções da cultura: perspectivas críticas feministas. Maceió: Edufal, 2017. Florianópolis: Editora da UFSC, p. 819-825.

.; LOURENÇO, Laureny. (Orgs.). (2019). Literatura e ecologia: trilhando novos caminhos críticos. Maceió: Edufal.

GAARD, Greta; STOCK, Simon; OPPERMANN, Serpill (ed.). (2013). International perspectives in feminist ecocriticism. New York and London: Routledge.

GAARD, Greta. (2017). "Novos rumos para o ecofeminismo: em busca de uma ecocrítica mais feminista. In: BRANDÃO, Izabel et. al. (Orgs.) Traduções da cultura: perspectivas críticas feministas. Maceió: Edufal. Florianópolis: Editora da UFSC, p. 783-818.

HOOKS, bell. (2015). "Mulheres negras: moldando a teoria feminista”. Revista Brasileira de Ciências. Políticas, n. 16, p. 193-210.

HUMM, Maggie. (1989). The dictionary of feminist theory. New York, London: Harvester Wheatsheaf.

MORTON, Timothy. (2007). Ecology without nature: rethinking environmental aesthetics. Cambridge: Harvard University Press.

OPPERMAN, Serpil. (2012). "Bodily natures". Environmental ethics, v. 34, janeiro. Disponível em: <https://www.researchgate.net/publication/271166821>. Acesso em: 20 maio 2020.

PROCTER, Paul (Org.). (1995). Cambridge international dictionary of English. Cambridge: Cambridge University Press. 
SIMCIKOVA, Carla. (2007). To live fully here and now: the healing vision in the works of Alice Walker. Plymouth: Lexington Books.

WALKER, Alice. (1997). Anything we love can be saved: a writer's activism. New York: Ballantine Books.

Recebido em 30/05/2020.

Aceito em 21/o6/2020. 